Ophthalmologe 2018 · 115:1020 https://doi.org/10.1007/s00347-018-0774-1 Online publiziert: 24. August 2018 (c) Springer Medizin Verlag GmbH, ein Teil von Springer Nature 2018

CrossMark

Philipp Herrmann

Universitäts-Augenklinik Bonn, Bonn, Deutschland

\title{
Molekulargenetische Diagnostik bei Makula- und Netzhautdystrophien
}

Das neue molekulargenetische VerAuch vor der Erstbeschreibung der DNA-Struktur 1953 wurden monogenetische Netzhauterkrankungen durch Ophthalmologen charakterisiert. Fundoskopische Beobachtungen führten $\mathrm{zu}$ detailreichen Beschreibungen mit charakteristischen und noch heute eindringlichen Zeichnungen wie beispielhaft von der "juvenilen Makuladegeneration“ oder „Retinitis pigmentosa“, die unseren klinischen Sprachgebrauch bis heute beeinflussen. Einen neuen Impuls bei erblich bedingten Netzhauterkrankungen lieferte Mitte des 20. Jahrhunderts die Elektrophysiologie, die unter anderem eine Zuordnung in primäre Zapfenbzw. Stäbchenprobleme erlaubt und so ein umfassenderes Verständnis wie auch eine neue Nomenklatur ermöglichte. In den letzten Dekaden gab es weitere richtungsweisende Fortschritte zur Charakterisierung von erblich bedingten Netzhauterkrankungen: Zum einen eröffnete sich durch die konfokale Laserscanning-Ophthalmoskopie, im Besonderen durch die Fundusautofluoreszenz, ein funktioneller, bildgebender Aspekt, der es erlaubt den Netzhautmetabolismus in vivo longitudinal $\mathrm{zu}$ verfolgen und Rückschlüsse über Pathomechanismen abzuleiten. Zum anderen hat die Genetik seit der Sanger-Sequenzierung über die Entschlüsselung des menschlichen Genoms (Humangenomprojekt) hin zum Next-Generation-Sequencing (NGS) viele Meilensteine erreicht. Heutzutage ist die Mehrzahl der genetischen Ursachen von monogenetischen Netzhauterkrankungen bekannt und prägt in der genauen Benennung der Mutation die heutige Nomenklatur mit. ständnis hat auch zu neuen mutationsspezifischen Therapieansätzen geführt - allen voran der Gentherapie. Gerade eben wurde in den Vereinigten Staaten LUXTURNA ${ }^{\mathrm{Ts}}$ als Gentherapie für Patienten mit biallelischen RPE65Mutationen zugelassen - eine rasante Entwicklung, die seit den ersten Publikationen im Jahr 2008 innerhalb einer Dekade zur Zulassung geführt hat. Auch wenn der Langzeitverlauf nach Gentherapie aktuell nicht vollständig absehbar ist, kann man davon ausgehen, dass sich in Zukunft weitere mutationsspezifische Therapieansätze durchsetzen werden.

\section{》) Das neue molekulargene- tische Verständnis hat zu spezifi- schen Therapieansätzen, allen voran der Gentherapie, geführt}

In diesem Leitthema finden Sie zwei ausgewählte Artikel die Ihnen die Entwicklungen im Feld monogenetischer Netzhauterkrankungen näherbringen: Johannes Birtel et al. beleuchten aus Sicht der Kliniker die Rolle der Phänotypisierung von erblich bedingten Erkrankungen der Netzhaut. Die Autoren gehen auf bildgebende Verfahren sowie diagnostische Schritte zur Diagnosestellung ein, zudem argumentieren sie für die Sinnhaftigkeit einer molekulargenetischen Diagnostik. Hanno Bolz berichtet in seinem Beitrag aus Sicht des Humangenetikers von der Revolutionierung der genetischen Diagnostik durch neue Methoden der Sequenzierung. Dabei führt er den Leser vom genetischen
Basiswissen zum Grundverständnis der neuen Methodik und beschreibt Indikation und Sinnhaftigkeit aktueller diagnostischer Möglichkeiten.

Ich wünsche Ihnen eine interessante Lektüre.

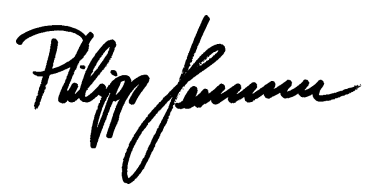

Philipp Herrmann

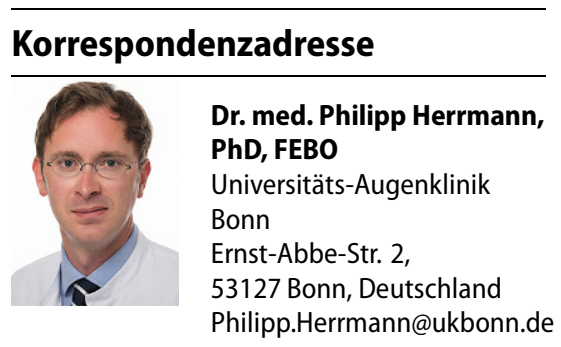

Interessenkonflikt. P. Herrmann: Forschungsförderung durch Heidelberg Engineering, Optos, Carl Zeiss MedicTec, CenterVue. 